Bargaining Toughness:

A Qualification of Level-of-Aspiration and Reciprocity Hypotheses

Edward J. Lawler

University of Iowa

Bruce K. MacMurray

Northeastern University

Journal of Applied Social Psychology (1980), 10(5), 416-430

Authorship is alphabetical. The authors wish to thank Samuel B. Bacharach for helpful comments on a prior draft. University of Iowa, Iowa City, Iowa 52242. Requests for reprints should be sent to Edward J. Lawler, Department of Sociology, 


\begin{abstract}
This research examined the interaction of initial bargaining stance and later concession strategy in dyadic bargaining. Experimental procedures pitted subjects against a programmed opponent and manipulated three variables: initial stance of the opponent across the first two bargaining rounds (tough vs. soft), deadlock vs. no deadlock, and subsequent concession strategy (tough, matching, soft). The results revealed that: (a) with a tough initial stance, a matching strategy produced greater yielding than tough or soft strategies; while in the context of a soft initial stance, a tough concession strategy produced more yielding than a matching or soft concession strategy; and (b) a prior deadlock reduced later concession making but did not specify or alter the effects of concession strategy. The research qualifies prior work based on level of aspiration and reciprocity theories by indicating that certain postures which mix toughness with softer stances are the most effective bargaining tactics.
\end{abstract}


Conflict resolution often occurs in the context of “explicit bargaining.” Explicit bargaining is essentially what happens when adversaries reach the bargaining table. Specifically, two or more parties with conflicting interests exchange offers and counteroffers in an attempt to develop an agreement (Chertkoff \& Esser, 1976). If and when conflict culminates in "explicit bargaining,” parties confront a delicate tactical issue-the primary concern of this paper: What type of concession stance or strategy will produce the most yielding by an adversary?

One can derive three contradictory answers to this question from prior research on bargaining: toughness, matching, and softness. With a tough concession stance, a bargainer makes smaller concessions in response to concessions by an adversary; while a matching stance calls for concessions equal to an adversary’s and a soft stance imples larger concessions in response to an adversary's concessions. The present research examines the effectiveness of these three concession stances. Given past support for all three concession stances, the major purpose is to specify conditions under which some stances are more effective than others.

Research on bargaining stance is generally related or organized around two theoretical notions: level-of-aspiration (Siegel \& Fouraker, 1960) and reciprocity (Gouldner, 1960; Nemeth, 1972; Osgood, 1962). Siegel and Fouraker's level-of- aspiration theory indicates that "It pays to be tough.” This theory assumes that concessions are a function of a bargainer's aspiration level and that aspirations are subject to manipulation by adversary. If an adversary adopts a tough stance, the bargainer's aspirations should decrease, while a soft stance should increase the bargainer's aspirations. The major prediction, therefore, is that tougher stances will extract larger concessions from a bargainer than softer stances (Siegel \& Fouraker, 1960).

On the surface, bargaining research appears to provide substantial support to the level-ofaspiration hypothesis. There are, however, serious problems with this general conclusion. 
Neither the theory nor related research had dealt adequately with the temporal dimensions or limitations of a tough bargaining stance. A strict interpretation of level-of-aspiration theory suggests toughness throughout the bargaining, i.e., a tough initial stance followed by continued toughness is the most effective bargaining strategy. This implies an interaction effect between initial stance and subsequent concession strategy. However, research on level-of-aspiration theory either confounds the initial and subsequent stance, yielding incomplete and uninterpretable findings on the interaction effect, or examines only one of these variables to the exclusion of the other (see, for example, Benton, Kelley, \& Iiebling, 1972; Komorita \& Bames, 1969; Komorita \& Brenner, 1968; Michener, Vaske, Schleiffer, Plazewski, \& Chapman, 1975; Yukl, 1974b). Furthermore, a close examination of research that deals with only one of these variables at a time (initial or subsequent stance) shows conflicting implications for level-ofaspiration theory. Research on initial stance (tough vs. soft) tends to support level-of-aspiration theory (Chertkoff \& Conley, 1967; Liebert, Smith, Hill, \& Keiffer, 1972; Yukl, 1974a), while research on concession strategies (subsequent to the initial stance) reveals enough departures from and even contradictions of level-of-aspiration theory to call into question its applicability beyond the initial or early period of the bargaining (Esser \& Komorita, 1975; Hamner, 1974). One purpose of the present research is to clarify these issues by examining three concession strategies (tough, matching, soft) in the context of different initial stances.

The major alternative to level-of-aspiration theory is reciprocity (Gouldner, I960; Nemeth, 1972; Osgood, 1962). In application to bargaining, one can distinguish two variants of reciprocity. The first one, hereafter labelled the "naive” version of reciprocity, assumes that (1) a cultural norm of reciprocity stipulates that people should help those who help them, reward those who reward them, etc. (Gouldner, 1960), and (2) that this cultural norm impinges on the behavior 
of parties in conflict just as (and as much as) it does on the behavior of the parties in nonconflict or predominantly cooperative relations. The implication is that a soft strategy will engender quicker and larger concessions from a bargainer. If, in response to a concession a party makes a larger concession, this should elicit greater yielding by a bargainer on the next round and, thereby, expedite the negotiations. Thus, from the standpoint of this "naive” version, consistent softness should engender the largest concessions and the greatest likelihood of agreement. Empirical support for this “naive” version of reciprocity is relatively scant, primarily because research on explicit bargaining has not included concession strategies that are softer than a matching one. However, some recent research suggests that a reward or reinforcement strategy, whereby a bargainer not only matches the other's concession but also rewards the concession by exceeding it, can be an effective means of eliciting concessions from a bargainer (Wall, 1977). The results of the Wall study provide some support for the "naive” version of reciprocity; however, Wall did not manipulate initial stance or compare consistent softness with consistent toughness and mixed stances, as will be done in the present research.

A second version of reciprocity, hereafter labelled the "vigilant” version, can be developed from Osgood’s (1962) GRIT—Graduated Reciprocation in Tension Reductionmodel and related research on reciprocity (Hamner, 1974). This approach implies more caution than the "naive" version of reciprocity and less intransigence than level-of-aspiration theory. The basic idea is that establishing reciprocal concession making is the key problem in bargaining; but, one cannot assume that parties in conflict will feel bound by the reciprocity norm, given the mutual distrust which characterizes conflict relationships (Osgood, 1962). A “vigilant” approach to reciprocity suggests that consistent softness will lead to exploitation rather than reciprocity; while, consistent toughness will tend to backfire and produce an impasse in negotiations. 
The "vigilant” version of reciprocity implies that a mixture of tough and softer strategies will produce the most yielding by a bargainer. Specifically, toughness in the early phases of the bargaining or until an impasse is created will generate respect and avoid exploitation. Beyond the initial phases of bargaining, however, a reciprocal (i.e., matching) concession stance will extract the largest concessions from the opponent. Thus, a "vigilant” approach to reciprocity suggests that initial toughness combined with a later matching strategy will produce the greatest concessions.

The foregoing prediction is consistent with the basic thrust or “spirit” of Osgood's (1962) GRIT model, but it neglects the fact that GRIT is directed primarily at deadlocked negotiations (Hamner, 1974; Hamner \& Yukl, 1977; Osgood, 1962). This raises an important question: Will a matching concession strategy be more effective than a tougher stance only if there is a prior deadlock? The evidence on this issue is inconclusive because research has not made explicit comparisons of deadlock vs. no deadlock conditions. One study established a deadlock across all experimental conditions and manipulated a programmed opponent’s concession strategy (Hamner, 1974). The programmed opponent made concessions that were $50 \%, 75 \%$, or $100 \%$ of the subject's, and the results indicated that the matching (100\% reciprocity) strategy produced greater concessions than tougher stances. However, while the Hamner (1974) study ostensibly supports the GRIT notion, other research has observed the same results, i.e., a matching strategy is more effective than tougher strategies, with conditions of no prior deadlock held constant (Esser \& Komorita, 1975; Komorita \& Esser, 1975). To extend prior research, the present study manipulates conditions of deadlock vs. no deadlock and examines tough, matching, and soft concession strategies in the context of these two conditions. Based on the GRIT model (Hamner, 1974; Hamner \& Yukl, 1977; Osgood, 1962), one would expect a deadlock by concession 
strategy interaction, indicating that a matching strategy is more effective than toughness only under conditions of a prior deadlock. ${ }^{3}$

To summarize, the research is organized around two hypotheses. First, and most important, there should be an interaction effect between initial stance (tough vs. soft) and subsequent concession strategy (tough, matching, soft). Level-of-aspiration theory suggests that this interaction will indicate that consistent toughness (i.e., tough initial combined with a tough subsequent strategy) is the most effective posture; "naive” reciprocity suggests consistent softness; and "vigilant” reciprocity suggests that the most effective stance will be a combination of a tough initial stance followed by a matching concession strategy. The second hypothesis is a deadlock by subsequent strategy interaction, indicating that a matching strategy is more effective than a tough one only in the context of a prior deadlock.

${ }^{3}{ }^{3}$ It should be noted that this hypothesis is only a partial representation of the GRIT model, and that this research is not intended as a comprehensive test of the GRIT model per se. The reason is that we believe the GRIT model places undue emphasis on unilateral initiatives. Specifically, Osgood suggests that a deadlock can be broken and reciprocity ultimately established through small, unilateral initiatives. Once a pattern of reciprocity is established, further unilateral initiatives can be used to increase the magnitude of reciprocal concession making (Osgood, 1962). However, the importance of unilateral initiatives as a pathway to reciprocal concession making is open to question. Such initiatives may be helpful under very specific circumstances, e.g., where there is extreme time pressure, high costs attached to conflict, and parties are hopelessly deadlocked. Under less extreme circumstances, unilateral initiatives may be an unnecessary risk. A bargainer might simply wait for the opponent to make a concession and then reciprocate it, or make one small concession and await some response. The present research is concerned with more general bargaining circumstances and, therefore, deemphasizes the role of unilateral initiatives. The only sense in which unilateral initiatives are included in this research is that the programmed opponent does make the first concession after the deadlock has been established. 
Method

\section{Design and Subjects}

A $2 \times 2 \times 3$ factorial design manipulated the initial bargaining stance (tough vs. soft), deadlock (no deadlock vs. deadlock), and concession strategy (tough, matching, soft). One hundred and twenty college student (female) volunteers were randomly assigned to one of the 12 experimental conditions (10 per cell). All subjects played the role of buyer in a bilateral monopoly setting adapted to an inter-nation context.

\section{Procedures}

Subjects were scheduled in groups of 4 to 6 . After they arrived, the experimenter randomly assigned subjects to one of two rooms. Subjects took a seat in separate cubicles within each room and read written instructions. The instructions explained that to maintain anonymity, they would be paired at random with one of the persons in the other room. One of them would be the buyer for a nation called Beta, and the other would be the seller for a nation called Alpha. In fact, all subjects assumed the role of Beta's buyer-representative and were presented with programmed feedback from Alpha’s representative.

The bargaining was concerned with the price of iron ore. The instructions indicated that the two nations had engaged in preliminary discussions but found that their offers were very far apart. In these initial discussions, Beta (the buyer) had offered a price of $\$ 5.00$ per ton, while 
Alpha had suggested a price of $\$ 12.00$ per ton. Subjects’ task was to bargain for as low a price as possible.

The instructions indicated that subjects’ pay for the experiment would depend on how much they agreed to pay for the iron ore. The instructions contained an "outcome list," indicating subjects’ profit at each of 29 potential agreement prices (in $25 £$ intervals from $\$ 5.00$ to $\$ 12.00$ ). Subjects' own profit at each price level was stated in terms of points, ranging from 100 points to 1,550 points. There was an inverse, linear relationship between subjects' own profit and price levels, such that the lower price, the greater their own profit. In the event of no agreement, subjects would ostensibly win the minimum profit on the “outcome list” (i.e., 100 points). The use of points prevented subjects from having exact, precise information on their own monetary pay at each price level. The instructions indicated that the experimenter would use a complex formula to transform their points into money at the end of the experiment. Furthermore, consistent with related research (Hamner, 1974; Yukl, 1974a, 1974b), subjects did not have information on their opponent's profit or pay at each price level. The instructions indicated that the opponent receives more profit with higher price levels but explained that, as in many realworld settings, bargainers will know only their own profit at various price levels.

Subjects also learned from the instructions that the bargaining would take place through written offers across a series of rounds. On each round, bargainers would send one written offer to each other. The programmed opponent (i.e., seller for Alpha) made the first offer on each round and, therefore, subject was placed in the position of accepting or rejecting the last offer of the opponent. When making an offer on a given round, bargainers had three options: (a) stick with and repeat their last offer, (b) accept the programmed opponent's offer, or (c) make a 
concession. The only restrictions on the bargaining were that subjects had to confine their offers to one of the 29 price levels on the "outcome list," and they could not retract earlier concessions. Bargaining continued until an agreement was reached or time ran out. Subjects did not know the maximum number of rounds. They were informed that they would have a maximum of 15 to 30 rounds and that they would be notified when they had 5 rounds left (notification occurred via standardized written notes in order to avoid verbal communication from the experimenter to subjects during the bargaining). The reason for giving subjects a range of possible maxi- mums is that it was necessary to extend the number of rounds in the deadlock condition to make sure the subsequent-concession manipulation could be in force for the same number of rounds across conditions (see below).

\section{Experimental Manipulations}

Initial bargaining stance. The programmed sellers' (opponent) offers on the first two rounds manipulated the initial stance. In the tough condition, the seller made an offer of $\$ 12.00$ on round 1 and $\$ 11.75$ on round 2, while in the soft condition the seller made offers of $\$ 11.00$ and $\$ 10.25$ on rounds 1 and 2, respectively.

Deadlock vs. no deadlock. Based on pretesting, a deadlock was defined as three consecutive rounds on which both bargainers “stick,” i.e., make no concession. To induce this condition, the programmed opponent stopped making concessions on round 3 and continued to stick until subject made three consecutive no-concession offers. On the round following the satisfaction of this criterion, the subsequent concession strategy went into effect. In the no- 
deadlock condition, the deadlock phase was simply deleted and the subsequent-concession strategy went into effect on round 3.

Concession strategy. The concessions of the programmed seller were contingent on the magnitude of subject's prior concessions. In the tough condition, the magnitude of seller's concession was $50 \%$ of subject's; in the matching condition, the seller equaled the concession magnitude of subject (100\%); and, in the soft condition, the seller conceded $150 \%$ of subject's concessions. The programmed opponent's concession strategy was manipulated across a maximum of 13 rounds. In the no-deadlock condition, this means that the maximum number of rounds for bargaining was 15 (i.e., 2 for the manipulation of initial stance and 13 for the manipulation of subsequent concession stance). In the deadlock condition, the maximum number of rounds consisted of 15 plus the number it took to satisfy the deadlock criterion (i.e., average of 4 rounds).

The concession manipulation was induced at comparable periods in the deadlock and nodeadlock conditions. In the no-deadlock condition, the manipulation started on round 3 and the magnitude of the opponent's concession was contingent on subject's movement between rounds 1 and 2. The first round after the deadlock is the equivalent of round 3 in the no-deadlock condition. Consequently, the programmed opponent’s “deadlock breaking” concession was based on the difference between subject's round 1 and last deadlock offer. 


\section{Dependent Variables}

Concession magnitude and concession frequency were the most important variables for testing the hypotheses. Concession magnitude was measured in two ways. First, the second-tolast offer by subject reflects the overall magnitude and also avoids the "end effects" that can occur due to extreme time pressure on the last round. The second measure is the magnitude of concessions while the concession strategy is in force (i.e., 13 rounds-from the end of round 2 in the no-deadlock condition and from the end of the deadlock in the deadlock condition). Concession frequency was measured as a proportion, i.e., by dividing the number of concessions in the post-deadlock (or post round 2) phase by the number of bargaining rounds (i.e., maximum 13 across all conditions). In addition, the paper will report data on the length of the bargaining (i.e., number of rounds in the post-deadlock or post round 2 phase) and agreements.

\section{Results}

Table 1 contains the mean values for the dependent variables: concession magnitude, concession frequency, bargaining time, and agreement. 


\section{Concession Magnitude}

Overall magnitude. A three-way analysis of variance revealed main effects for initial stance and concession strategy as well as the anticipated initial stance by concession strategy interaction. The two main effects support level-of- aspiration theory, i.e., a tough initial stance engendered larger concessions than a soft initial stance, $F(1,108)=3.61, p<.06$; and a tough subsequent strategy produced the largest concessions with a matching strategy second and a soft strategy last, $F(2,108)=11.33, p<.001$; however, the interaction of initial stance and concession strategy supersedes and specifies these main effects, $F(2,108)=8.00, p<.001$. Table 2 presents the means for this interaction effect.

Insert Table 2 Here

The nature of the interaction was examined via Duncan's multipe-range test for post hoc comparisons (Kirk, 1968). The results indicate that the toughmatching and soft-tough conditions produced larger concessions than any other conditions, while the soft-soft condition produced smaller concessions than the other conditions (see Table 2). These pairwise comparisons have two interrelated implications. First, of the three major postures identified in the introduction, the tough-matching stance produced the largest concessions, consistent toughness was second, and consistent softness was last. Second, initial stance qualified the effects of concession strategy. With a tough initial stance, a matching strategy produced larger concessions than a tough or soft strategy; on the other hand, in the context of initial softness, a tough concession strategy extracted larger concessions than a matching strategy which, in turn, engendered more yielding 
than the soft strategy. Overall, the results support the vigilant-reciprocity hypothesis over naivereciprocity and level-of- aspiration hypotheses, but also indicate that an alternative mixed strategy (i.e., soft-tough) is as effective as vigilant reciprocity (i.e., tough-matching).

The deadlock manipulation does not affect overall concession magnitude and the data do not support the deadlock by concession strategy interaction suggested by some theory and research (Hamner, 1974; Hamner \& Yukl, 1977; Osgood, 1962).

Concession magnitude in the subsequent phase. The analysis revealed a deadlock main effect, indicating that a prior deadlock reduced the magnitude of concessions, $F(l, 108)=$ $21.25, p<.001$. Once again, the data did not support the hypothesized deadlock by concession strategy interaction effect, $F<1$. It appears that a prior deadlock diminishes subsequent concessions but that it may not affect the overall magnitude of a bargainer's concession during the bargaining. The other results are consistent with the data on overall concession magnitude. Main effects for initial stance, $F(1,108)=72.88, p<.001$, and for concession strategy, $F(2,108)=$ 5.25, $\mathrm{p}<.007$, revealed the same pattern as did an initial stance by concession strategy interaction, $\mathrm{F}(2,108)=3.82, \mathrm{p}<.02$.

\section{Concession Frequency}

The results showed three main effects and a significant initial stance by concession strategy interaction. The main effects indicated that concessions were more frequent following a deadlock, $F(l, 108)=7.03, p<.009$, more frequent with a tough rather than a soft initial stance, $F(l, 108)=13.75, p<.001$, and more frequent with softer concession strategies, 
$F(2,108)=3.78, p<.03$. However, once again, the interaction specifies the effects of initial stance and concession strategy, $F(2,108)=8.02, p<.001$.

Post hoc comparisons showed results that generally dovetail with the results for concession magnitude. Specifically, under conditions of initial toughness, a matching strategy extracts more frequent concession than a tough concession strategy (Duncan's $p<.05$ ), while under conditions of initial softness, the tough concession strategy engenders more frequent concessions than a matching concession strategy (Duncan's $p<.05$ ). Thus, in accord with the results for concession magnitude, the relative effectiveness of tough vs. matching strategies is contingent on the initial bargaining stance.

The only departure from the results for concession magnitude occurred for the soft strategy. In the context of initial toughness, the soft strategy is superior to a tough strategy and not significantly different from the matching strategy; while, in the context of initial softness, the soft strategy is not significantly different from a tough strategy. In sum, while a soft concession strategy generally reduces concession magnitude, it appears that it can extract more frequent concessions than other strategies under some conditions.

\section{Additional Analyses}

Length of bargaining. The number of rounds (in the subsequent phase- maximum $=13$ ) is an indicator of how difficult it is for parties to deal with the conflict. The results revealed only a main effect for concession strategy. Overall, the means suggest that bargainers used most of the time available to bargain across all three conditions but that a tough concession strategy slightly increased the amount of bargaining time, $F(2,108)=4.06, p<.02$. This is suggested not only 
by the direction of the means but also by a comparison of the tough condition with the average of the matching and soft conditions, $t=2.62, p<.02$ two-tailed.

The main effects for the initial stance $(F=2.0, n s)$ and deadlock $(F=2.37, n s)$ as well as the interactions do not reach statistical significance.

Likelihood of agreement. Agreements were reached in two ways: 70\% of the subjects accepted one of the programmed opponent's offers; while in $30 \%$ of the cases, subjects forced the programmed opponent to agree by making an offer above the level to be offered by the programmed opponent on the next round. Given the procedures of the study, subject was responsible for the agreement in either case.

The overall $X^{2}$ for the $2 \times 2 \times 3 \times 2$ table reveals a significan t overall association between the independent variables and the dependent variables, $X^{2}(18)=40.79, p<.01$. The pattern of results (see Table 1) indicates that the source of this effect lies with the initial-stance and concession strategy variables. Ryan's procedure for making post hoc, pairwise comparisons of binary data was used to identify the significant differences. This method adjusts the significance levels for each comparison or $X^{2}$ such that the experimentwise error remains constant (Linton \& Gallo, 1975; Ryan, 1960). The pairwise comparisons showed that a toughtough strategy produced significantly fewer agreements than any of the other conditions (all $p<$ .05); and, there were no other significant pairwise differences. Thus, the only posture which clearly inhibits the likelihood of agreement is consistent toughness.

Deadlock data. For cases in the deadlock condition, a one-way analysis of variance for initial stance was done on the length of the deadlock and magnitude of subject's concessions during the deadlock. The results show only a marginal effect of initial stance on the length of the 
deadlock, $F(1,59)=2.99, p<.10 ; M s=3.7$ (tough) vs. 4.2 (soft), and no effect on the magnitude of concessions within the deadlock phase, $F<1 ; M s=38$ (tough) vs. 49 (soft).

\section{Discussion}

Prior research on concession strategy has yielded contradictory results. Some studies indicate that a matching strategy produces more concessions than tougher strategies (Esser \& Komorita, 1975; Hamner, 1974; Komorita \& Esser, 1975); others suggest that tough concession strategies generate the greatest concessions (Bartos, 1970; Benton et al., 1972; Komorita \& Bames, 1969; Komorita \& Brenner, 1968; Rubin \& Dimatteo, 1972; Yukl, 1974a, 1974b), and still others imply that softness produces the greatest concessions (Wall, 1977). Given the contrasting implications of prior research, the present study investigated initial bargaining stance as a possible qualifying condition.

Three theoretical notions suggest initial stance by concession strategy interaction effects. A strict interpretation of level-of-aspiration theory (Siegel \& Fouraker, 1960) suggests that consistent toughness is the most effective stance. One version of reciprocity (i.e., "naive”) stipulates that a cultural norm of reciprocity will exert sufficient pressure on bargainers to make consistent softness the "best" stance (Gouldner, 1960); while a second version of reciprocity (i.e., "vigilant”) suggests that a mixture of initial toughness with subsequent matching is the most effective strategy.

The results of the experiment indicate that initial bargaining stance does specify the effects of the concession strategy. Given a tough initial stance, a matching concession strategy produces larger and more frequent concessions than a tough stragegy, and larger (but not more 
frequent) concessions than a soft strategy. The initial stance by concession strategy interaction supports the mixed strategy proposed by the "vigilant" version of reciprocity in that matching is the most effective strategy only with a tough initial stance. The data fail to support either the consistent toughness prediction from level-of- aspiration theory or the consistent softness prediction of Wall’s (1977) reinforcement approach.

The results also suggest conditions under which a tough concession strategy is effective. Specifically, with a soft initial stance, a tough strategy extracts larger and more frequent concessions from a bargainer than a matching strategy and larger, though not more frequent, concessions than a soft strategy. This result reveals a qualification or specification of level-ofaspiration theory and supporting research (see Benton et al., 1972; Komorita \& Brenner, 1968; Yukl, 1974a). A tough initial stance is effective only when combined with a matching concession strategy; while a tough concession strategy is effective only when combined with a soft initial stance.

On the most general level, this study indicates that certain combinations of toughness with softer strategies produce the greatest yielding by the opponent (i.e., tough-matching, softtough). The question is, why do these forms of tactical variation engender the most concessions? An answer can be developed from a general hypothesis offered by Chertkoff and Esser (1976). In their review of this literature, Chertkoff and Esser imply that concession strategies are important primarily because of the impressions they "give off' to opponents. Their proposal is that a "firm but reasonable” impression will yield the greatest concessions from an opponent. A bargainer must appear "firm" in order to avoid exploitation and to lower the other's aspiration level; but, at the same time, a bargainer must convey a willingness to make concessions, i.e., appear reasonable. Behavior which gives undue attention to only one of these dimensions, firm or 
reasonable, may engender less yielding than behavior which takes account of both impressionmanagement dimensions.

Applied to the present study, a mixture of initial toughness followed by matching or initial softness followed by toughness could strike a balance between the "firm" and "reasonable" dimensions. The overall stance in both of these conditions might be construed as “conciliatory toughness”. A matching strategy in the context of initial toughness conveys a willingness to make concessions but within an overall firm stance which does not leave the bargainer open to exploitation. The initial softness-subsequent toughness condition combines more diverse elements than the tough-matching one, but the impression "given off' may be comparable. With this approach, the bargainer is tough throughout most of the bargaining but demonstrates a willingness to make concessions via a soft initial stance. The soft initial stance could open one to exploitation, but the rather quick switch to toughness probably assures that the initial stance will not seriously mislead the other bargainer. In sum, it appears that tactical variation in a bargainer's stance is one way for bargainers to “give off' impressions that maximize yielding by the opponent.

Turning to effects of a deadlock, theoretical treatments in Osgood (1962) and Hamner (1974) suggest that a deadlock will (a) reduce concessions and (b) make necessary a change in the bargaining strategy toward reciprocation or matching. The results indicate that a deadlock does reduce the frequency and magnitude of concessions in the subsequent phase, but this effect occurs across different concession strategies. None of the results support the notion that "softer" strategies are necessary when there is a prior deadlock (Hamner, 1974; Osgood, 1962).

The results for the deadlock condition are strengthened by the fact that the deadlock in this study did not place bargainers under more time pressure or increase costs. The absence of 
any confound with cost or time enables one to argue from the results that a deadlock per se has minimal effect on bargaining. However, future research should determine whether deadlocks with varying cost or time pressure produce different effects on bargaining behavior. It is conceivable that the hypotheses articulated by Osgood (1962) and Hamner (1974) apply only to circumstances where the deadlock increases time pressure and/or costs. That is, deadlock effects may simply be time or cost pressure effects. The present research shows that when a deadlock is not confounded with time pressure or costs, it does not affect the success of alternative concession strategies, as suggested by Osgood (1962) and Hamner (1974).

A prior deadlock, however, does reduce future concessions. This result can be interpreted in light of subjects’ behavior during the deadlock phase of the experiment. Subject typically made some concessions $(M=43.5)$ during the deadlock phase or before the deadlock criterion (i.e., three consecutive stick rounds) was fulfilled. The reduction in the magnitude of future concessions may have been a response, in part, to what subjects had conceded during the deadlock phase while getting nothing in return. The theoretical implication is that the effects of a deadlock on subsequent concessions may not occur if parties yield a comparable amount while the deadlock is developing. On the other hand, in cases where one party yields more than the other as a deadlock develops (as in the present study), that party may expect some redress after the deadlock and yield somewhat less than if there was no deadlock. Thus, the effect of a deadlock on future concessions should be contingent on differential yielding by parties during the deadlock.

To conclude, this research questions the practical advice implied in level-of- aspiration and reciprocity theories. Level-of-aspiration theory advises bargainers to be tough throughout the bargaining, while the "naive” version of reciprocity recommends consistent softness. This 
research indicates that consistent toughness is likely to beget toughness and prevent conflict resolution while softness will produce lower concession levels than other bargaining postures. The overall implication of this research is that the tactical advice implied in Osgood's (1962) GRIT model—being tough, then match the other's concessions-is the most effective way to maximize the yielding of the opponent. 
Table 1

TABLE 1

CONCESSION MAGNITUDE CONCESSION PROPORTION, NUMBER OF ROUNDS, AND AGREEMENTS BY EXPERIMENTAL CONDITION

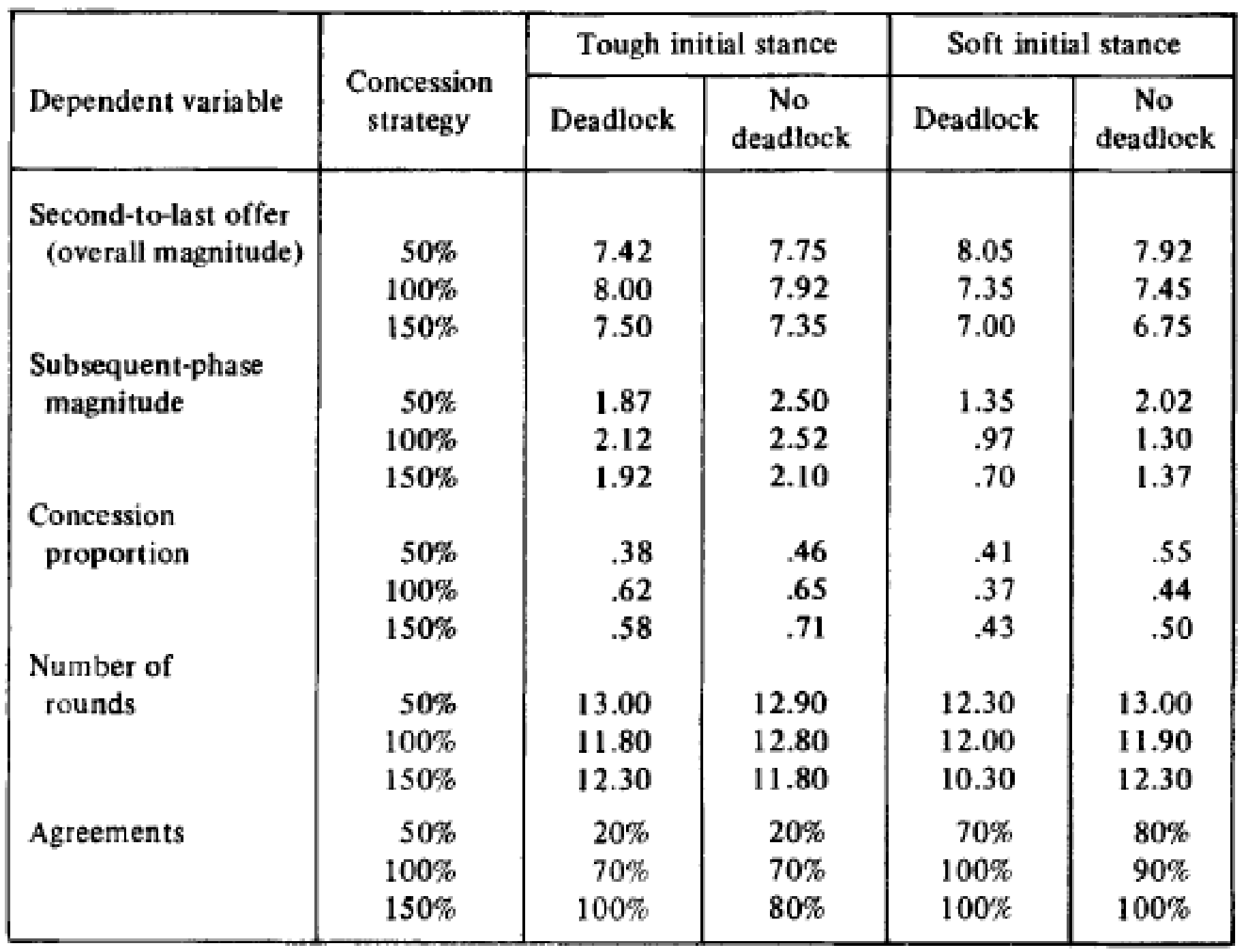


Table 2

TABLE 2

SECOND-TO-LAST SUBJECT OFFER BY INITIAL STANCE AND CONCESSION STRATEGY

\begin{tabular}{|c|c|c|}
\hline \multirow{2}{*}{ Concession strategy } & \multicolumn{2}{|c|}{ Initial stance } \\
\cline { 2 - 3 } & Tough & Soft \\
\hline $\begin{array}{c}\text { Tough } \\
(50 \%) \\
\text { Matching } \\
(100 \%) \\
\text { Soft } \\
(150 \%)\end{array}$ & $7.58_{\mathrm{b}}$ & $7.98_{\mathrm{a}}$ \\
\hline
\end{tabular}

Note. High numbers mean higher overalli concession magnitude by subject. Means with different subscripts are significantly different, while those with the same subscripts are not significantly different. (Duncan's $p<.05$.) 


\section{References}

Bartos, O. J. Determinants and consequences of toughness. In P. Swingle (Ed.), The structure of conflict. New York: Academic Press, 1970.

Benton, A. A., Kelley, H. H., \& Liebling, B. Effects of extremity of offers and concession rate on the outcomes of bargaining. Journal of Personality and Social Psychology, 1975, 12, 170-180.

Chertkoff, J. M., \& Conley, M. Opening offer and frequency of concession as bargaining strategies. Journal of Personality and Social Psychology, 1967, 7, 181-185.

Chertkoff, J. M., \& Esser, M. A review of experiments in explicit bargaining. Journal of Experimental Social Psychology, 1976, 7, 426-443.

Esser, J. K., \& Komorita, S. S. Reciprocity and concession making in bargaining. Journal of Personality and Social Psychology, 1975, 31, 864-872.

Gouldner, A. W. The norm of reciprocity: A preliminary statement. American Sociological Review, 1960, 25, 161-178.

Hamner, W. C. Effects of bargaining strategy and pressure to reach agreement in a stalemated negotiation. Journal of Personality and Social Psychology, 1974, 30, 458-467.

Hamner, W. C., \& Yukl, G. A. The effectiveness of different offer strategies in bargaining. In D. Druckman (Ed.), Negotiations. New York: Sage Publications, 1977.

Kirk, R. E. Experimental design: procedure for the behavioral sciences. Belmont, Calif.: Brooks/Cole, 1968.

Komorita, S. S., \& Brenner, A. R. Bargaining and concession-making under bilateral monopoly. Journal of Personality and Social Psychology, 1968, 6, 349-353. 
Komorita, S. S., \& Esser, J. K. Frequency of reciprocated concession in bargaining. Journal of Personality and Social Psychology, 1975, 32, 699-705.

Liebert, R. M., Smith, W. P., Hill, J. H., \& Keiffer, M. The effects of information and magnitude of initial offer on interpersonal negotiation. Journal of Experimental Social Psychology, 1968, 4, 431-441.

Michener, H. A., Vaske, J. J., Schleiffer, S. L., Plazewski, J. G., \& Chapman, L. J. Factors affecting concession rate and threat usage in bilateral conflict. Sociometry, 1975, 38, 6280.

Nemeth, C. A critical analysis of research using the prisoner's dilemma paradigm for the study of bargaining. In L. Berkowitz (Ed.), Advances in experimental social psychology. New York: Academic Press, 1972.

Osgood, C. An alternative to war or surrender. Urbana: University of Illinois Press, 1962.

Pruitt, D. G., \& Drews, J. L. The effects of time pressure, time elapsed, and the opponents’s concession rate on behavior in negotiation. Journal of Experimental Social Psychology, 1969, 5,43-60.

Rubin, J., \& Dimatteo, M. R. Factors affecting the magnitude of subjective utility parameters in a tacit bargaining game. Journal of Experimental Social Psychology, 1972, 8, 412-426.

Ryan, T. A. Significance tests for multiple comparison of proportions, variances, and other statistics. Psychological Bulletin, 1960, 57, 318-328.

Siegel, S., \& Fouraker, L. E. Bargaining and group decision making. New York: McGraw-Hill, 1960.

Wall, J. A. Operantly conditioning negotiator’s concession making. Journal of Experimental Social Psychology, 1977, 13,431-440. 
Yukl, G. A. Effects of the opponent's initial offer, concession, magnitude, and concession in frequency on bargaining behavior. Journal of Personality and Social Psychology, 1974, 29, 326-333. (a)

Yukl, G. A. Effects of situational variables and opponent concessions on a bargainer's perception, aspirations and concession. Journal of Personality and Social Psychology, 1974, 29, 227-236. (b) 